\title{
Tests on hypotheses about osteoarthritis and hip joints
}

\author{
N Y P Afoke, P D Byers, W C Hutton
}

Polytechnic of

Central London, London,

United Kingdom

N Y P Afoke

Institute of

Orthopaedics,

University of London,

London,

United Kingdom

P D Byers

Department of

Orthopaedics,

Emory University,

Atlanta, Georgia, USA

W C Hutton

Correspondence to:

Dr W C Hutton,

Department of

Orthopaedics,

Emory University,

69 Butler Street,

SE Atlanta,

GA, 30303, USA

Accepted for publication 16 July 1991
Abstract

Hypotheses suggesting that hip joints which develop osteoarthritis are congruent, have a single area of peak pressure, and have peak pressure which exceeds normal values were tested. Of 100 hip joints examined on necropsy; two showed an early stage of osteoarthritis and the geometry and pressure distribution under load were assessed in these joints. One joint was congruent, in agreement with the hypotheses, but the other was incongruent. In both joints there were several areas of high pressure, the number and location of which depended on the orientation of the joint. The measured values of pressure in the congruent joint exceeded values found previously in normal hip joints. In the incongruent hip joint the peak pressures were within normal limits.

Studies of osteoarthritis, especially in the early stages, are complicated by problems of definition and recognition criteria. The complexities are indicated by the wide range of postulated aetiologies and pathogenesis. ${ }^{1}$ In spite of strenuous efforts, firm agreement has not been reached on details of the subsets which have been identified clinically and epidemiologically. This contributes to the problem of classification of osteoarthritis.

This diversity of data and opinion necessitates selection in formulating problems for investigation. We were stimulated by the ideas of

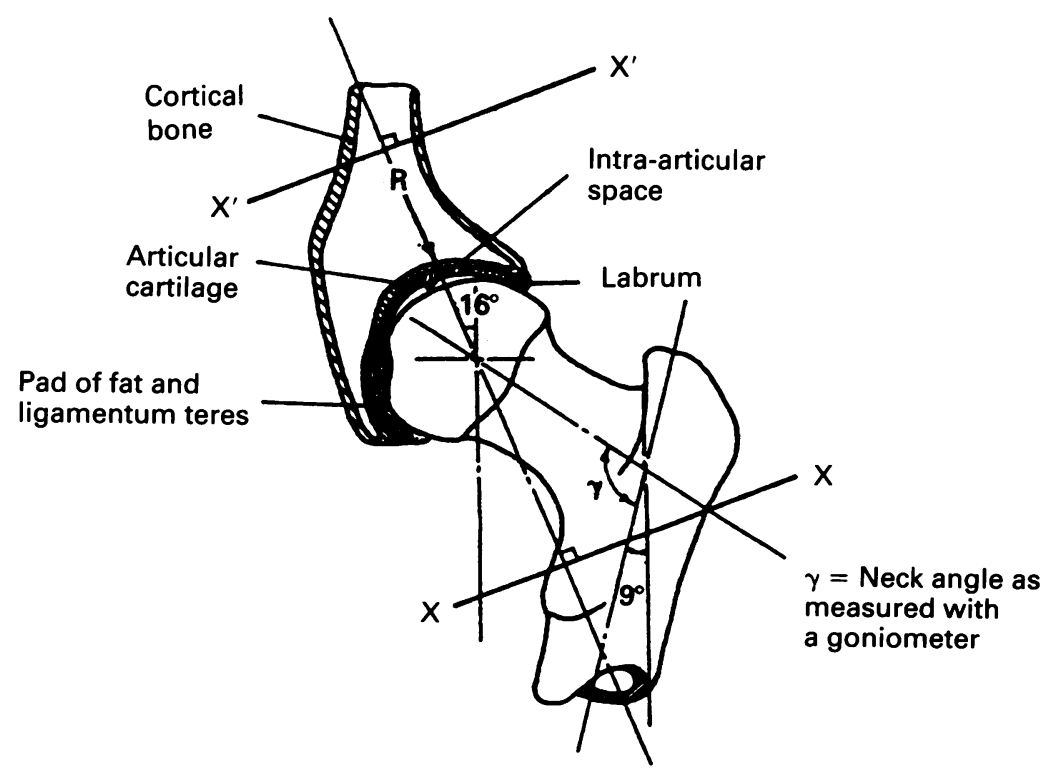

Figure 1 Schematic diagram of a hip joint showing the angles of the femoral head and shaft and the cutting planes $\left(X-X\right.$ and $\left.X^{\prime}-X^{\prime}\right)$ perpendicular to the resultant force acting on the joint in the coronal plane.
Bullough et $a^{2}$ to study the mechanics of the hip joint at necropsy. ${ }^{3-5}$ Bullough et al ${ }^{2}$ postulated that the incongruent geometry of the hip 6 protects it from developing osteoarthritis by optimising the distribution of the load. This required a means of recognising normal and osteoarthritic joints, for which we used the criteria of Byers et al. ${ }^{7}$ In a study of $368 \mathrm{hip}$ joints at necropsy, they established the distinction between progressive (osteoarthritic) and non-progressive lesions of articular cartilage on the basis of site and macroscopic appearance, which they corroborated by histological ${ }^{8}$ and statistical $^{9}$ analysis. Of the 100 hips collected for mechanical studies in this work, two were in an early stage of osteoarthritis which were excluded from the studies of normal subjects, but which were ideal for testing the hypothesis of Bullough et al. ${ }^{2}$

This hypothesis was restated by Bullough. ${ }^{10}$ The compressibility of cartilage brings greater areas of it into contact as the load is increased, thereby maintaining a constant load per unit area. The absence of incongruence, whether developmental or acquired through joint remodelling, has the effect of creating a single peak of pressure exceeding normal limits and could lead to failure of the cartilage and the onset of osteoarthritis. Atrophy of the cartilage least in use by reason of the geometry (that

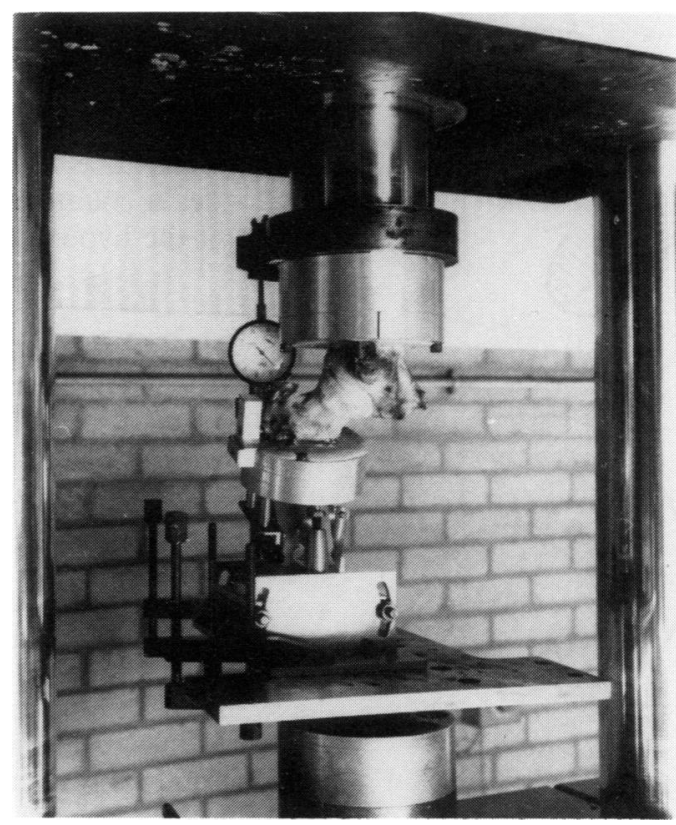

Figure $2 A$ joint in position for testing. The femoral head is fixed to an adjustable swivel, on the cross beam of

a Mayes servo controlled testing machine, allowing rotation in the horizontal and vertical planes. The acetabulum is fixed in its natural position relative to the femoral head. 


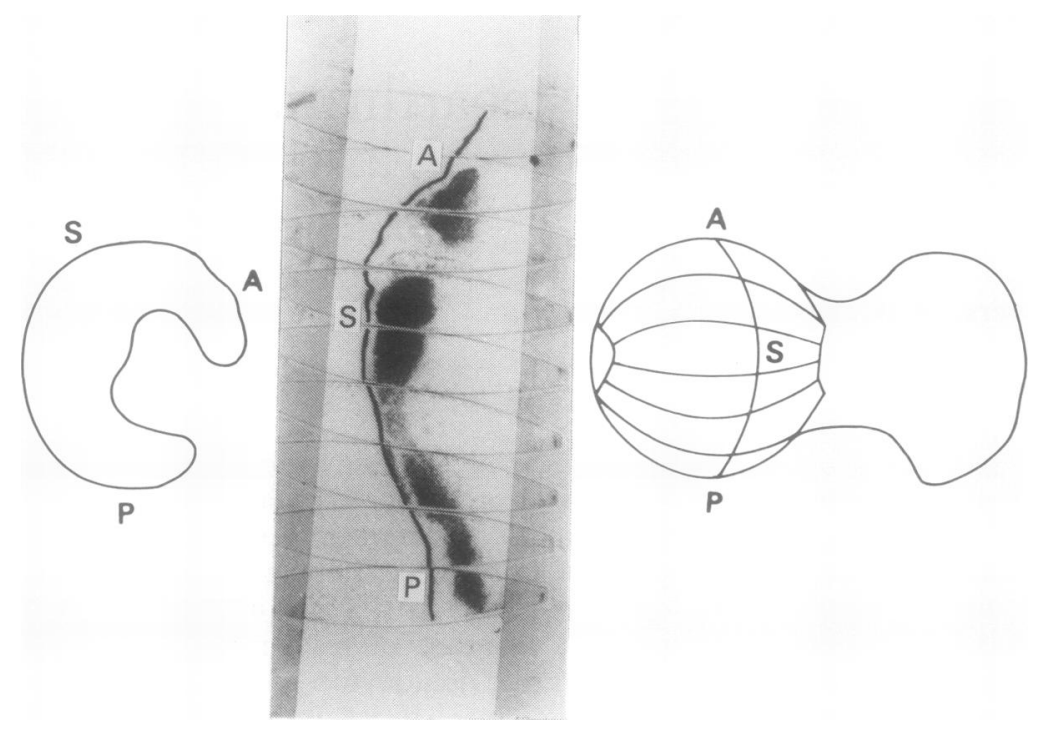

Figure 3 A right femur viewed from above; the acetabulum and upper layer of the pressure film sandwich have been taken off and turned face upwards. In this position the recording surface of the paper is visible and is a true view of the pressure distribution on the acetabulum, and a mirror image of that on the head. The trace of the acetabular rim is the fixed reference (see text). $P=$ posterior; $A=$ anterior; $S=$ superior (the letters ' $S$ ' are superimposed when assembled.

Specimen

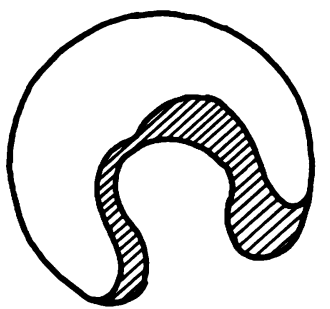

$27^{\circ}$ flexion

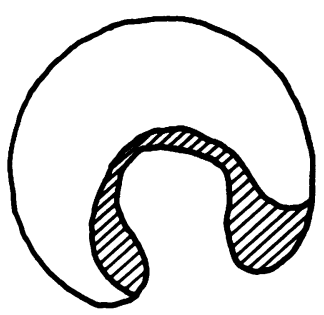

$0^{\circ}$ neutral

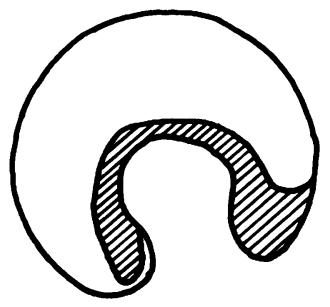

$18^{\circ}$ extension

Figure 4 Schematic diagram showing the outline of the casts of the interarticular space (shaded areas) obtained at $40 \mathrm{~N}$ for specimen 1 (from a 92 year old woman). cartilage lying in the acetabular roof) was proposed to be a contributory factor to its subsequent failure when demands were made on it as the protective geometry was lost.

The statements which could be tested using the two joints in the early stages of osteoarthritis are that hip joints which develop osteoarthritis (a) are congruent, (b) have a single area of peak pressure, and $(c)$ have a peak pressure which exceeds that in normal subjects.

We fully recognise that two hips cannot be a basis for statistical analysis; but, with a frequency of $1-2 \%$ of the early stages of osteoarthritis in a necropsy population a very substantial collecting system would be required to achieve appreciable numbers of suitable joints. Indeed, our collection system only yielded two such joints in four years. Despite this, two specimens are sufficient to test a hypothesis in as far as any failure of the observations to conform with the predictions constitutes a counter example and a degree of failure of the hypothesis. ${ }^{11}$

\section{Materials and methods}

Two pairs of hip joints from women 92 and 68 years old were obtained at necropsy. In each pair one joint was at an advanced stage of osteoarthritis and the other was at an early stage. ${ }^{7-9}$ This paper reports the two joints with early lesions.

Specimen 1 was the right hip of the 92 year old woman in which the lesion was located posteriorly. Here the cartilage was reduced to half the thickness of the adjacent smooth cartilage, as determined from a fine detail radiograph of a slab cut through the lesion.

Specimen 2 was the left hip of the 68 year old woman. Visually, the outline of the joint was unaltered except for the fine velvety texture of the cartilage surface. Confirmation of early changes came from a comparison of three plugs of $10 \mathrm{~mm}$ diameter removed from the anterior (lesional), superior, and posterior surfaces for comparative stiffness tests.

The specimens were stored frozen at $-20^{\circ} \mathrm{C}$. In preparation for testing they were thawed, disarticulated, and cleared of all soft tissue, including the labrum. The ilium and femoral shaft were cut across planes $\left(\mathrm{X}-\mathrm{X}\right.$ and $\mathrm{X}^{\prime}-\mathrm{X}^{\prime}$, fig 1) perpendicular to the resultant force acting on the joint in the coronal plane; the angle at which it acted remained the same in that plane during flexion, the neutral position, and extension. ${ }^{12}$ The prepared components were placed in cups with their cut surfaces resting on the cup base, where they were held by dental cement and a wood screw into the bone. The acetabular cup was fixed to the ram surface of a Mayes servo controlled hydraulic testing machine. The head cup was fitted into a rig fixed to the cross beam of the testing machine (fig 2). The rig allowed the direction of applied force to be adjusted as required. Throughout the study the joint was kept moist with Ringer's solution by wrapping it in moistened cloths during a test and by soaking for 30 minutes between tests.

To obtain a cast of the interarticular space, the specimen was set in the testing position at the required orientation and a small load of $40 \mathrm{~N}$ was applied (the procedure is fully described in Afoke and co-workers). ${ }^{35}$ The position of the acetabulum in relation to the femoral head was recorded by a dial gauge; the specimen was then disarticulated. A measure of the casting material, Impregum $F$ (a polyether rubber impression material, manufactured by ESPE, Fabrik Pharmazeutischen Praparate, Seefeld, Oberbay, Germany) was placed in the acetabulum and the joint was rearticulated to the original dial gauge position. A previous study has shown that the interarticular space, as represented by the casts, is variable in size and shape in the same specimen at different orientations. ${ }^{4}$ It was clear from that study that the relative geometry of a joint could be categorized from the characteristics of the cast. The joint was considered to be incongruent if $(a)$ a large femoral head relative to its acetabulum or $(b)$ if a relatively small femoral head was seen. The joint was classified as congruent if the femoral head and acetabulum were similar in size. This classification meets our need for describing and classifying joint geometry.

The pressure sensitive film for determining the pressure distribution was Fujifilm (Prescale). This consists of two polyester films' with a combined thickness of $0.2 \mathrm{~mm}$. One film is coated with a layer of microencapsulated colour forming material, and the other with a colour developing material. Papers sensitive to four ranges of pressure are available; those covering 1-10 and 7-25 MPa were used here. In practice, the low range film was used first, and when a result near to $10 \mathrm{MPa}$ was obtained a second test with the higher range film was carried out. The colour which develops in the film is proportional to the applied pressure and can be quantitated in a densitometer after calibration. Calibration was performed using known loads applied to a plane ended cylinder. The pressure film was 
Specimen 2

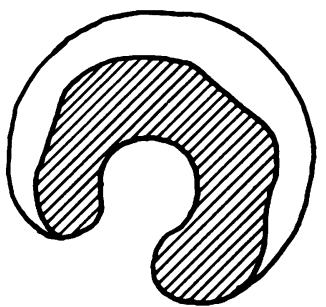

$27^{\circ}$ flexion

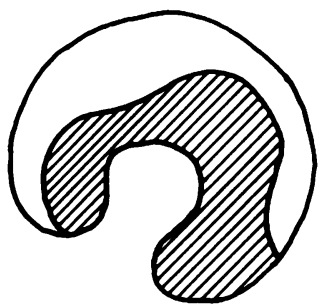

$0^{\circ}$ neutral

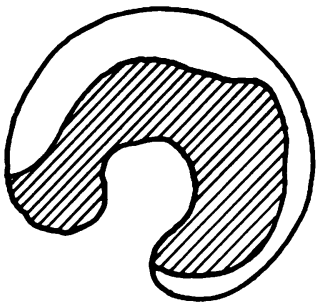

$18^{\circ}$ extension diagram showing the outline of the casts of the

interarticular space (shaded areas) obtained at $40 \mathrm{~N}$ for specimen 2 (from a 68 year old woman).
Figure 5 Schematic

ased in the instantaneous pressure mode during the calibration and the experiments. This means that the load is applied within five seconds and removed within another five seconds without a dwell time. Pressure measurements, using Fujifilm, have been carried out on faceted joints of the spine, ${ }^{13}$ on patellofemoral joints, ${ }^{14}$ and on normal hip joints. ${ }^{5}$ In the last of these studies pressure contours in the loaded area of the hip were drawn, and the anterosuperior surface of the cartilage was found to bear the maximum pressure, ranging from 5 to $10 \mathrm{MPa}$. The table shows the values that have been reported using this technique and the technique of instrumented prostheses and acetabula.

\section{EXPERIMENTAL PROCEDURE}

The paired halves of the film were prepared for use by cutting into lanceolate shapes so that they could form a hemisphere when applied to the femoral head. A layer of cling film was first applied tightly to the femoral head; the cut out pressure film rested on this and was held in position by adhesive tape at each end. To avoid water damage, another layer of cling film was stretched over the femoral head, and the specimen was then ready for testing. The pressure tests were made with the joint in three positions and with loads simulating three phases of the walking cycle: heel strike at 3.3 times body weight; neutral at 1.3 times body weight; and pre-toe off at four times body weight. Upon completion of each test, the pressure film was peeled off the femoral head and mounted on a board. Figure 3 shows a schematic femoral head and acetabulum together with a pressure print. On each, an equivalent point has been marked; this shows the convention adopted for viewing the print. A double beam analogue microdensitometer in the reflection mode was used to record the absorbance of the print. These were then used in conjunction with the calibration graph to draw the pressure contour lines manually.

Specimen 1
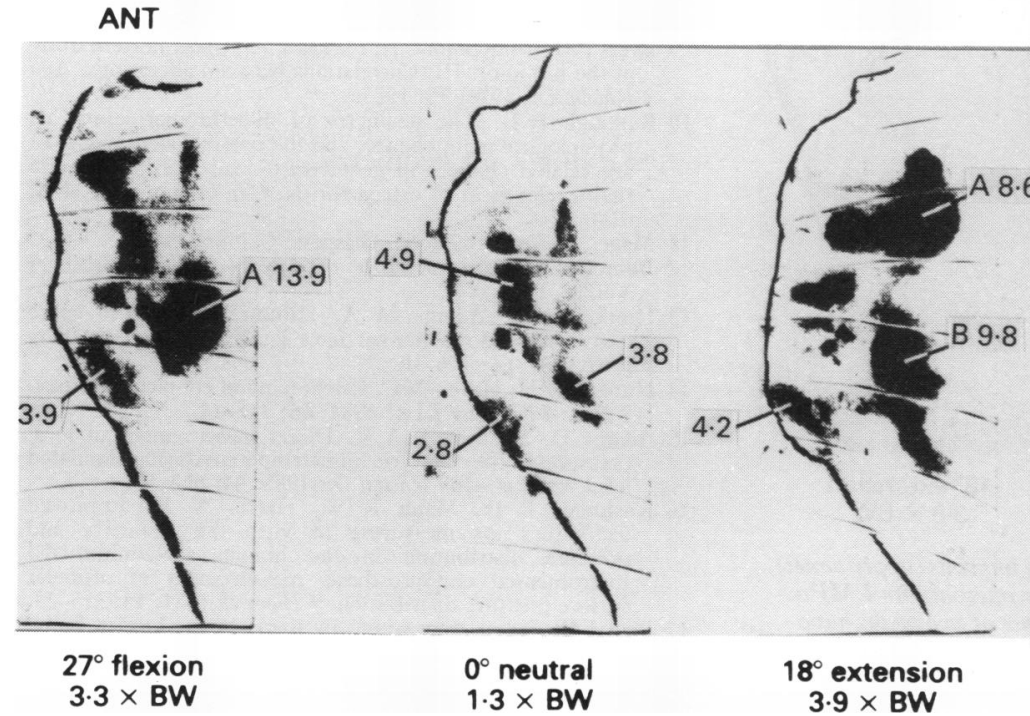

Figure 6 Pressure imprints from specimen 1 showing the location (marked $A$ and $B$ here and in fig 7) and magnitude of the pressure maxima (MPa). $B W=$ body weight.

\section{Results}

JOINT GEOMETRY

Figures 4 and 5 show the outline of the casts in the three positions tested for specimens 1 and 2, respectively. Those from specimen 1 show very little interarticular space, suggesting a nearly congruent geometry. In contrast, specimen 2 shows an interarticular space in all three positions, indicative of a femoral head larger than its acetabulum. ${ }^{4}$

\section{PRESSURE MEASUREMENT}

Figure 6 shows the pressure prints and the maximum levels in high pressure areas for the nearly congruent joint (specimen 1). Figure 7 shows these high pressure areas in relation to the cartilage lesion. In flexion there is one area of above normal pressure (area A of $13.9 \mathrm{MPa}$ ). This is the highest pressure we have ever recorded for a hip joint. ${ }^{5}$ In the neutral position the maximum pressure is $4.9 \mathrm{MPa}$. In extension there are two areas of high pressure: area $\mathrm{A}$ at 8.6 and area $B$ at $9.8 \mathrm{MPa}$. Finally, it can be seen that area $A$ is a high pressure site in both flexion and extension, whereas area $B$ is only so in extension.

Figure 8 shows the pressure prints and the contour lines for the three positions tested in specimen 2. These are characteristic of an incongruent joint where the head is larger than its acetabulum. Unlike the prints for specimen 1, the contact areas are large with numerous high pressure focal sites. In flexion the cartilage anterosuperiorly and posteriorly is subjected to pressures up to 10.6 and $9 \mathrm{MPa}$, respectively. In the neutral position these same areas have reduced pressures of 7 and $8 \mathrm{MPa}$, whereas in extension a maximum pressure of $8.5 \mathrm{MPa}$ was found anterosuperiorly. The cartilage lesion, lying anterosuperiorly, is therefore subjected to the maximum pressure in flexion and extension.

\section{Discussion}

The following conclusions may be drawn with

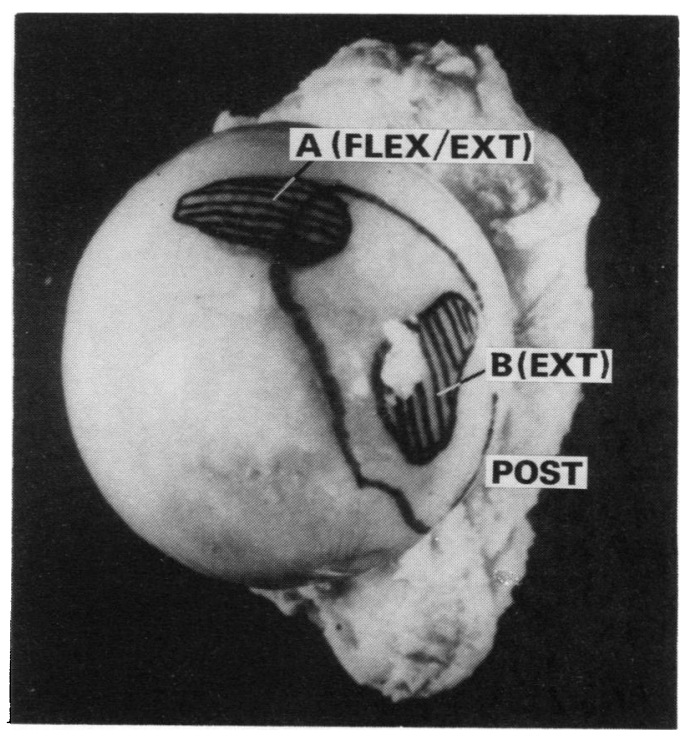

Figure 7 Medial view of the femoral head of specimen 1 showing the location of the high pressure sites. The thick line delineates the extent of the early progressive lesion and the hatching represents the high pressure areas in flexion and extension (marked $A$ and $B$ as in fig 6 ). 
respect to the hypotheses under test. In joints which develop osteoarthritis: $(a)$ the geometry is not necessarily congruent; $(b)$ the peak pressure is not necessarily distributed within a single area; and $(c)$ the peak pressure can exceed normal values.

\begin{tabular}{|c|c|c|}
\hline foint (measurement method) & Maximum pressure $(M P a)$ & Reference \\
\hline $\begin{array}{l}\text { Apophyseal } \\
\text { (Fujifilm) }\end{array}$ & $\begin{array}{l}5 \cdot 7 \text { at } 4^{\circ} \text { flexion } \\
6.4 \text { at } 0^{\circ} \text { neutral } \\
7 \cdot 3 \text { at } 4^{\circ} \text { extension }\end{array}$ & 13 \\
\hline $\begin{array}{l}\text { Patellofemoral } \\
\text { (Fujifilm) }\end{array}$ & $\begin{array}{l}2.0(0.4) \text { at } 20^{\circ} \text { flexion } \\
4.4(1.0) \text { at } 90^{\circ} \text { flexion }\end{array}$ & 14 \\
\hline$\stackrel{\text { Hip }}{\text { (Fujifilm })(n=5)}$ & $\begin{array}{l}8.28(2.34) \text { at } 27^{\circ} \text { flexion } \\
5.18(1.82) \text { at } 0^{\circ} \text { neutral } \\
7.76(1.57) \text { at } 18^{\circ} \text { extension }\end{array}$ & 5 \\
\hline $\begin{array}{l}\text { Hip } \\
\text { (with acetabulum } \\
\text { recorded by pressure } \\
\text { transducers) }\end{array}$ & $5 \cdot 26-8 \cdot 57$ & 15 \\
\hline $\begin{array}{l}\text { Hip } \\
\text { (using an endoprostbesis) }\end{array}$ & $9 \cdot 3-11 \cdot 1$ & 16 \\
\hline
\end{tabular}

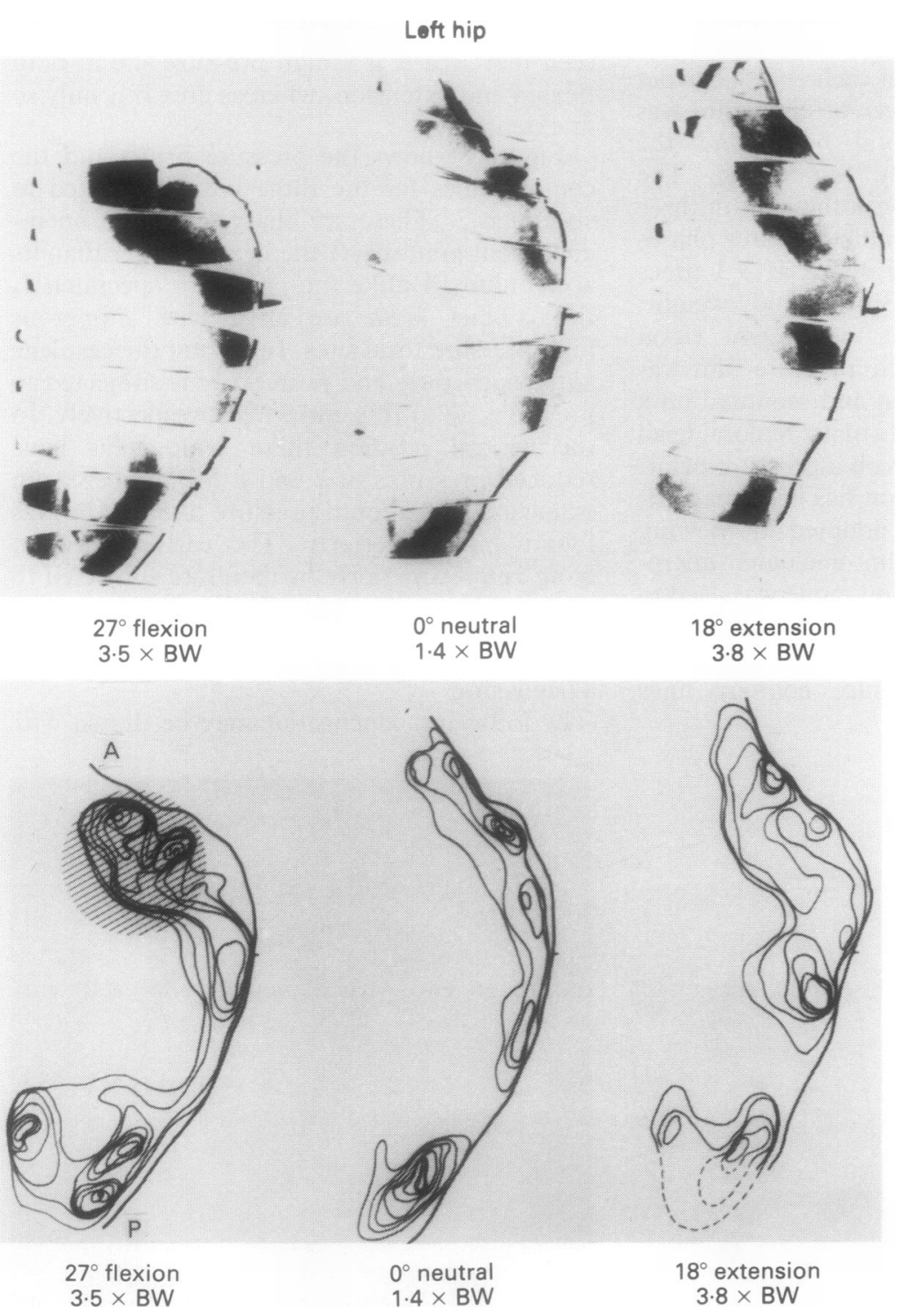

Figure 8 Left hip, specimen 2 (68 year old woman). The pressure imprints (upper panel) have been converted to pressure contours (lower panel). The contour intervals are $1 \mathrm{MPa}$. The pressure at any point can be read by counting the lines; the values of two peaks have been indicated because the lines are too close to count easily. The shaded circle is an approximation of the lesion on the femoral head superimposed on the pressure contours in flexion. $B W=$ body weight.
Osteoarthritis had been established in the two specimens for an unknown length of time. It would be reasonably safe to assume that this time is relatively short in the time scale of osteoarthritis, but it is more difficult to know its length relative to the time scale of joint remodelling. Moreover, there is no knowledge of remodelling rates. Indeed, although it is accepted that the surface contours of joints can be altered, there is scant detail of how it is achieved, ${ }^{18}$ or whether the extent of the surface which can be affected is sufficient to account for important alterations in congruency. Our earlier observations $^{3-5}$ were that the fit of the hip joint could be explained by the relative size of the parts, to alter which would require growth. Thus there remains the possibility that the current patterns of geometry and pressure are not the patterns of an earlier time, which may have been those predicted by the hypotheses. The samples needed to answer this question could be made available through a systematic hip joint collection service (such as proposed by Mankin et al), ${ }^{1}$ by selecting for study joints with apparent early osteoarthritis, or paired joints of which only one was diseased. In the latter case, probability suggests that some of the matching, visibly unaffected joints would be in an incipient stage of the disease, which might be possible to confirm by independent means.

Mankin H J, Brandt K D, Shulman L E. Workshop on the etiopathogenesis of osteoarthritis. Proceedings and recommendations. I Rheumatol 1986; 13: 1126-60.

2 Bullough P G, Goodfellow J, O'Connor J. The relation between degenerative changes and load bearing in the between degenerative changes and load bearing in
human hip. F Bone foint Surg [Br] 1973; 55: 746-58.

3 Afoke N Y P, Byers P D, Hutton W C. The incongruous hip joint: a casting study. $\mathcal{F}$ Bone foint Surg $[\mathrm{Br}]$ 1980; 62: $511-4$

4 Afoke N Y P, Byers P D, Hutton W C. The incongruous hip joint: a loading study. Ann Rheum Dis 1984; 43: 295-30

5 Afoke N Y P, Byers P D, Hutton W C. Contact pressures in the human hip joint. $\mathcal{f}$ Bone foint Surg $[\mathrm{Br}] 1987$; 69 536-41.

6 Walmsley T. The articular mechanism of diarthroses. 7 Bone Foint Surg 1928; 10: 40-5

7 Byers P D, Contepomi C A, Farkas T A. A postmortem study of the hip joint: including the prevalence of the features of of the hip joint: including the prevalence of the

8 Byers PD, Contepomi C A, Farkas T A. A postmortem study of the hip joint. II. Histological basis for limited and of the hip joint. II. Histological basis for limited and progressive

9 Byers P D, Contepomi C A, Farkas T A. A postmortem study of the hip joint. III. Correlations between alterations. Ann Rheum Dis 1976; 35: 122-6.

10 Bullough P G. The geometry of di-arthrodial joints, its physiological maintenance, and the possible significance of age related changes in geometry-to-load distribution and the development of osteoarthritis. Clin Orthop 1981; 156 61-6.

11 Magee B. Popper. 7th ed. Glasgow: Collins, 1978.

12 Bombelli R. Osteoarthritis of the hip. New York: Springer Verlag, 1976.

13 Dunlop $R$ B, Adams M A, Hutton W C. Disc space narrowing and the lumbar facet joints. $\mathcal{F}$ Bone foint Surg [Br] 1984; 66: 706-10.

14 Huberti H H, Hayes W C. Patellofemoral contact pressures. f Bone foint Surg [Am] 1984; 66: 715-24.

15 Adams D, Swanson S A V. Direct measurement of local Adams D, Swanson $S A$. Direct measurement of local pressures in the cadaveric human hip joint during sim

16 Rushfeldt P D, Mann R W, Harris W H. Improved techniques for measuring in vitro the geometry and pressure distribution in the human acetabulum-II Instrumented endoprosthesis measurement of articula surface pressure distribution. $\mathcal{f}$ Biomech 1981; 14: 315-23. 17 Paul J P. Forces transmitted by joints in the human body. Proc Inst Mech Eng 1987; 181 (3J): 8-15.

18 Sokoloff $\mathrm{L}$. Osteoarthritis as a remodelling process. I Rheu matol 1987; 14 (suppl): 7-10). 